\title{
OPTIMIZATION OF CERAMIC SHELL MOLD MATERIALS IN INVESTMENT CASTING
}

\author{
I. B.Dave ${ }^{1}$, V. N. Kaila ${ }^{2}$ \\ ${ }^{1}$ Head, Metallurgy Department, Dr. S. \& S. S. Gandhy Engg, \& Tech., Surat, Gujarat, India \\ ${ }^{2}$ Lecturer, Metallurgy Department, Government Polytechnic, Rajkot, Gujarat, India
}

\begin{abstract}
Ceramic shell investment casting process is used to produce high quality casting products with relatively close dimensional tolerance. The refractory material use as primary coat on shell mold of investment casting play a very important role to form surface finish. Zircon flour though costly, is being used as a primary slurry material in the ceramic shell investment casting process. To reduce the cost of primary slurry material, some alternate refractory material like, alumina, silica, used with zircon to enhance properties. The hardness test of the casted samples and micro-examination under binocular metallurgical microscope has been done to study the micro-characteristic evaluation. The result reveals that the ceramic shell contains $100 \%$ zircon primary refractory gives the best results.
\end{abstract}

Keywords: shell mold, refractory, slurry, investment casting

\section{INTRODUCTION}

Investment casting is also known as lost wax casting. Investment casting is widely used for producing complex geometries of ferrous and non-ferrous materials [1]. Much advancement made to the process due to the growth of technology. In investment casting, the ceramic molds are made by two different methods; the solid mold process and the ceramic shell process. The ceramic shell mold process has become predominant technique for major engineering applications [2].

The refractory materials use as primary slurry for ceramic shell mold of investment casting play an important role to develop quality casting. A better refractory implies no metal penetration and surface finish. The primary coat refractory material must be non-reactive with binder use to produce slurry as well as metal to be cast [3]. In investment shell mold prepared by applying a series of ceramic slurry coating to the pattern cluster. Silica, zirconia, alumina and aluminium silicate are commonly used for slurry to produce shell mold. Alumina is expensive refractory compare to zirconia. It is use for directional solidification processes. Other refractories like graphite, zirconia, yitria used with reactive alloys. The surface quality of casting determine by particle size and composition of slurry in mold making for investment casting [4].

Conventional corundum shell molds based on ethyl silicate binder and containing silicon dioxide that interact with heat resistant alloy components and alkaline admixtures present in corundum as well as partly decompose at high temperature. Mold binder destruction occurs resulting in its weakening and porosity increase [5].

The permeability of mold material is of high importance to the metal casting process. The mold must be capable of allowing gases to pass through the shell mold. If gases cannot exit the mold faster than it is filled, then air pressure increase within the mold. This buildup of incomplete mold filling, shell cracking and gas defect in casting [6].

The effect of alumina with zirconia and silica with zirconia on casting properties has been studied. Commonly zirconia alone use as primary coat material for shell mold of investment casting.

\section{LITERATURE REVIEW}

The alumina $\mathrm{Al}_{2} \mathrm{O}_{3}$ ceramic refractory is employed for the casting and directional solidification component having a high surface finish requirement. A ceramic mixture containing a large grain will produce a rough inner mold wall. This roughness is reproduced on casting surface. A slurry containing a large percentage of fines requires an excessive amount of binder and usually causes mold wall buckling [7].

In the investment casting time of drying from pattern to pour of ceramic mold is too long. Drying and following hardening of layer produced with using binder dissolve in water solutions is a much slower process than the alcohol as a solvent. This drying process can be accelerated by warming the mold or by blowing warm air. However such type of solution is not possible in the investment casting techniques, since mold warming cause deformation of wax model. Several industrial plants adopt colloidal binder and ethyl silicate as binders for the drying solution [8].

For this experiment, percentage of alumina, zirconia and silica mixture with zircon flour as primary coating has been changed and observed the effect on hardness of casting and microstructure characteristic of casted sample by investment 


\section{EXPERIMENTAL WORK}

For this experiment, percentage of alumina, zirconia and silica mixture with zircon flour as primary coating has been changed and observed the effect on hardness of casting and microstructure characteristic of casted sample by investment process. Experiments carried out in three stages to determine the effect of ceramic material. Ceramic composition selected as shown in table 1.

Table -1: Ceramic composition used for experiments

\begin{tabular}{|l|l|l|l|}
\hline Materials & $\begin{array}{l}\text { Experiment- } \\
1(\mathrm{Wt} . \%)\end{array}$ & $\begin{array}{l}\text { Experiment- } \\
\text { 2(Wt. \%) }\end{array}$ & $\begin{array}{l}\text { Experiment- } \\
\text { 3(Wt. \%) }\end{array}$ \\
\hline $\begin{array}{l}\mathrm{Zirconia} \\
\left(\mathrm{ZrO}_{2}\right)\end{array}$ & 100 & 50 & 70 \\
\hline $\begin{array}{l}\mathrm{Alumina} \\
\left(\mathrm{Al}_{2} \mathrm{O}_{3}\right)\end{array}$ & NA & 50 & NA \\
\hline $\begin{array}{l}\mathrm{Silica} \\
\left(\mathrm{SiO}_{2}\right)\end{array}$ & NA & NA & 30 \\
\hline
\end{tabular}

$\mathrm{NA}=$ Not used for respective experiment

\subsection{Material Selection}

The ceramic slurry used to produce sample for test consist zircon flour $\left(\mathrm{ZrO}_{2}\right)$, alumina $\left(\mathrm{Al}_{2} \mathrm{O}_{3}\right)$ and silica $\left(\mathrm{SiO}_{2}\right)$. Zircon flour selected with the mesh size of 100 mesh and 300 mesh for primary coating. Alumina has been added in zirconia with a mesh size number of 300 mesh. Fused silica used with mesh size number of 100 mesh.

\subsection{Design of Pattern}

Initial sample design was selected to produce pattern. Gating system was selected as metal poured from the top of the mold for steel casting. The mold material and gating material were made from the wooden materials produced master patterns.

\subsection{Development of Ceramic Slurry}

The composition of ceramic mold as shown in table 1 for investment casting was determined with $100 \%$ zircon for sample-1, 50\% Zircon ad 50\% Alumina for sample-2 and $70 \%$ zircon and $30 \%$ fused silica. A commercial synthetic binder used with slurry. The slurry was mixed properly with help of stirrer and maintained its optimum quality and consistency by regular monitoring.

\subsection{Development of Ceramic Shell}

Development of ceramic shell has been carried out three times to develop three experiments. Each time slurry composition was changed and process repeated to produce ceramic shell. A two-step process was used including dipping the pattern into the slurry then spraying the binder and refractory powder on it. The first coat was developed by dipping the pattern into the ceramic slurry. It was fine, dense and uniform layer avoiding the entrapment of air bubble. The pattern was lifted and dried in the air. Pattern was again dipped into the slurry to ensure missed area of pattern. Finally pattern was allowed to air dry. It was take approximately 20 to 30 minutes complete drying process.

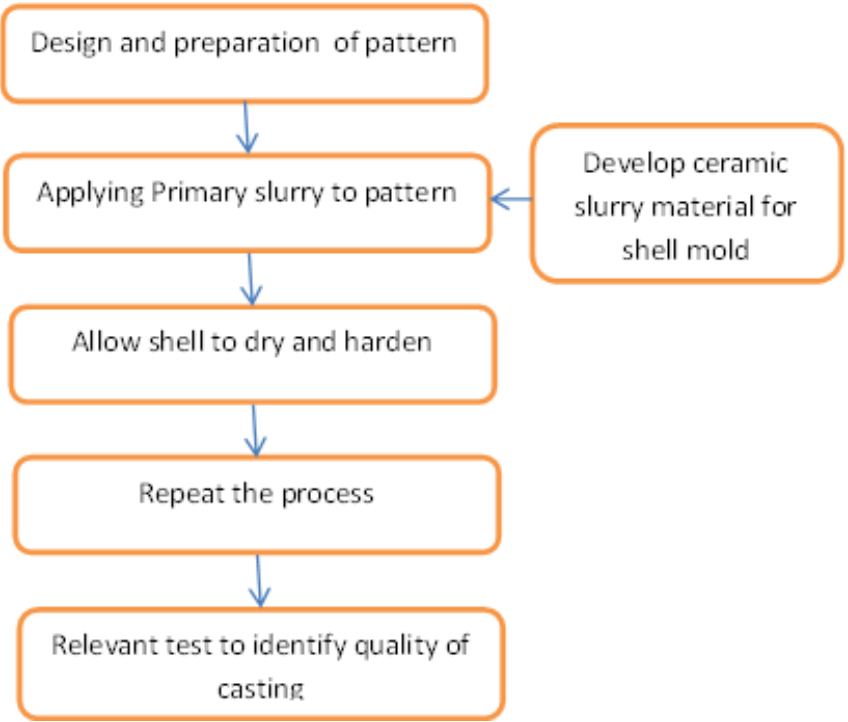

Fig -1: Process flow diagram of invention

The mold was dried and second layer was built by dipping in the same slurry to increase shell thickness. The mold was allowed to dry 20 to 30 minutes after each dipping. The process of dipping the pattern into the slurry and air drying was repeated until the required thickness of 6 to $7 \mathrm{~mm}$ of shell mold. The sealing coat was applied to the mold. The sealed coat was applied to bind any residual refractory material to the surface preventing loose particles falling away from the finish investment mold.

The process of shell mold building was time consuming as each coat slurry needs to be dried prior to application of subsequent layers. The air drying period of ceramic mold was reduced to using electric fan, but higher drying rate can cause the shell to crack.

\subsection{Firing of Ceramic Mold}

The process of drying of shell mold took 6 to 7 days to remove complete moisture and fired into the electric furnace to melt out the pattern maintaining $1100^{\circ} \mathrm{C}$ for $2 \mathrm{hrs}$. The mold allowed to sinter to obtain require hardness for 1 hour.

\section{RESULTS AND DISCUSSION}

\subsection{Visual Inspection}

Visual inspection of low alloy steel (A216-WCB grade) samples were carried out as shown in Figure-2. There were three samples produced by separate three experiments including the variation in ceramic materials of shell mold used in investment casting. 


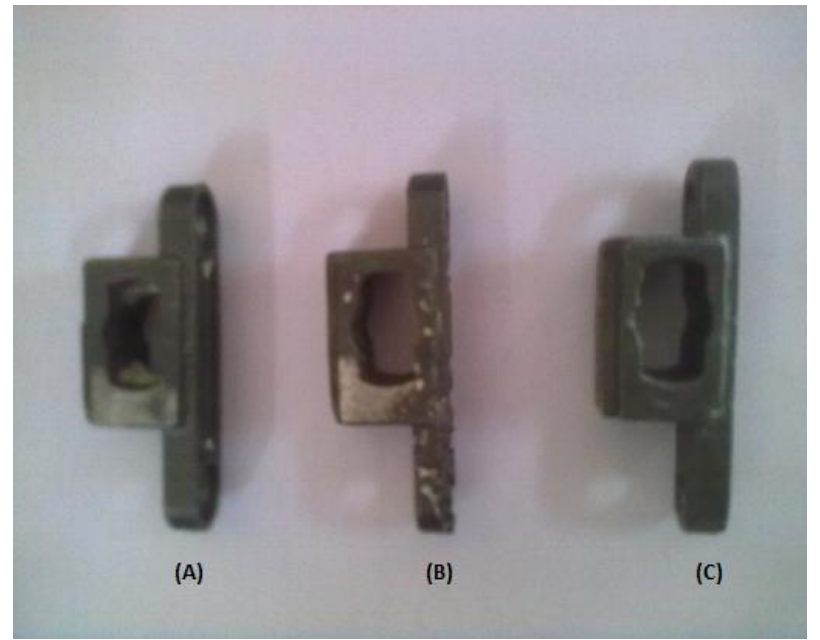

Fig -2: Visual inspection of investment casted samples

As shown in Figure-2, sample A which was casted by experiment-1 consist $100 \%$ zircon ceramic. It shows excellent surface finish and no marks of any cracks and surface distortion in terms of surface defect. Sample B for experiment 2 consist of $50 \%$ zircon and $50 \%$ alumina observed good surface finish of casted sample. In this experiment also no marks of surface defects observed on casted samples. In sample $\mathrm{C}$ for experiment 3 consist of $70 \%$ zircon and $30 \%$ silica, surface finish was observed fair compare to experiment 1 . On the surface erosion marks observed which reflect the improper bonding of ceramic materials of shell mold.

\subsection{Chemical Composition Analysis}

In the experiments selected samples were subjected to spectroscopy test to compare chemical composition. Following table 2 represents the chemical composition of samples

Table -2: Chemical composition of casted samples

\begin{tabular}{|l|l|l|l|}
\hline Element & $\begin{array}{l}\text { Exp-1 } \\
\text { Sample A }\end{array}$ & $\begin{array}{l}\text { Exp-2 } \\
\text { Sample B }\end{array}$ & $\begin{array}{l}\text { Exp-3 } \\
\text { Sample C }\end{array}$ \\
\hline $\mathrm{C}$ & 0.241 & 0.157 & 0.140 \\
\hline $\mathrm{Si}$ & 0.725 & 0.392 & 0.333 \\
\hline $\mathrm{Mn}$ & 0.490 & 0.291 & 0.271 \\
\hline $\mathrm{S}$ & 0.0324 & 0.0103 & 0.0079 \\
\hline $\mathrm{P}$ & 0.0159 & 0.0178 & 0.0171 \\
\hline $\mathrm{Cr}$ & 0.700 & 0.550 & 0.545 \\
\hline $\mathrm{Ni}$ & 0.122 & 0.133 & 0.124 \\
\hline $\mathrm{Mo}$ & 0.0153 & 0.0189 & 0.0173 \\
\hline $\mathrm{Cu}$ & 0.0418 & 0.0463 & 0.0455 \\
\hline $\mathrm{Nb}$ & 0.0043 & 0.0020 & 0.0019 \\
\hline $\mathrm{Ti}$ & 0.0032 & 0.00044 & $<0.0002$ \\
\hline $\mathrm{V}$ & 0.0053 & 0.0041 & 0.0039 \\
\hline
\end{tabular}

For any material quality always comprised with the chemical composition. From the table 2, carbon content decreased with experiment 2, which was contains $50 \%$ alumina with zircon ceramic shell. In experiment 3, which contains $30 \%$ silica with zircon observed reduction in carbon content. In spite of care taken during preparation of slurry composition inferior results observed in terms of chemical composition. The weight percentage of carbon reduces from 0.24 to 0.15 in experiment 2 and 3 , which leads decarburization during directional solidification of casting. Silicon and manganese also reduced with carbon. The reduction in micro-constituents in the casted samples due to interaction between wall of ceramic shell mold and the surface of the casting.

\subsection{Hardness Test}

The Rockwell hardness test carried out on casted samples to find out hardness gained in the product. Hardiness results were obtained by using Rockwell hardness tester applied $110 \mathrm{~kg}$ load at B scale with the help of 1/16" steel ball indenter. Table 3 shows the hardness results of the specimen.

Table -3: Ceramic composition used for experiments

\begin{tabular}{|l|l|l|l|l|}
\hline Materials & \multicolumn{3}{|l|}{$\begin{array}{l}\text { Rockwell Hardness } \\
\text { (HRB) }\end{array}$} & $\begin{array}{l}\text { Avg. } \\
\text { HRB }\end{array}$ \\
\hline Sample A & 145 & 144 & 143 & 144 \\
\hline Sample B & 143 & 143 & 141 & 142 \\
\hline Sample C & 142 & 143 & 141 & 142 \\
\hline
\end{tabular}

From the hardness results it ensures the visual results. In the sample A contain $100 \%$ zircon have excellent mechanical properties. However minor variation observed in sample B and sample $\mathrm{C}$.

\subsection{Micro-Examination}

To study of solidification characteristic micro-examination was carried out on Binocular metallurgical microscope (Almicro MM3) for the casted samples.

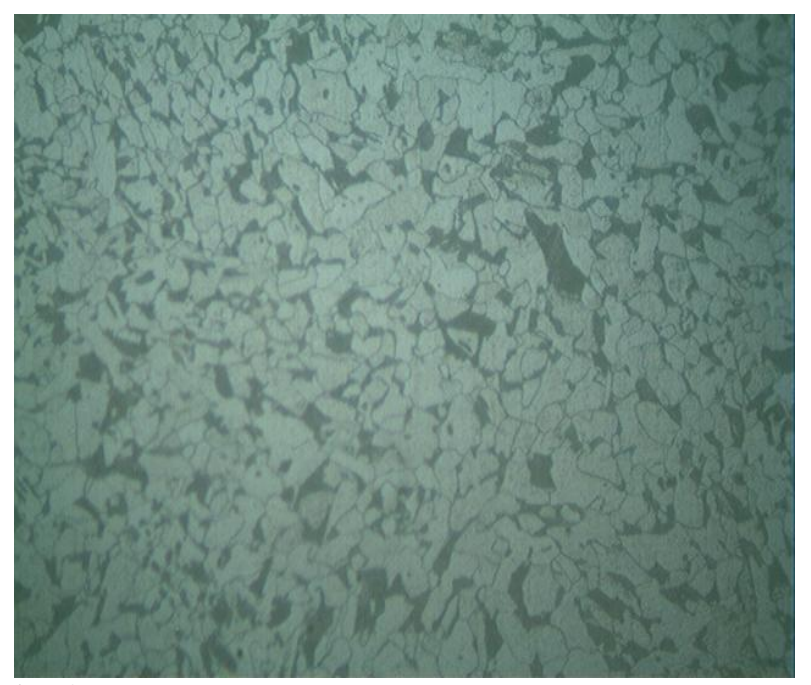

Fig -3: Microphotograph of sample A contain 100\% zircon (400X) 
The microphotograph of sample A in Figure 3 reveals that the perfect microstructure contains uniform distribution of cementite and pearlite phases. Zircon was used as refractory slurry for shell mold. Zircon produce better microstructure due to its fine grain characteristic and it provide directional solidification. The directional solidification produces uniform grain size and no imperfection in microstructure of the low alloy steel.

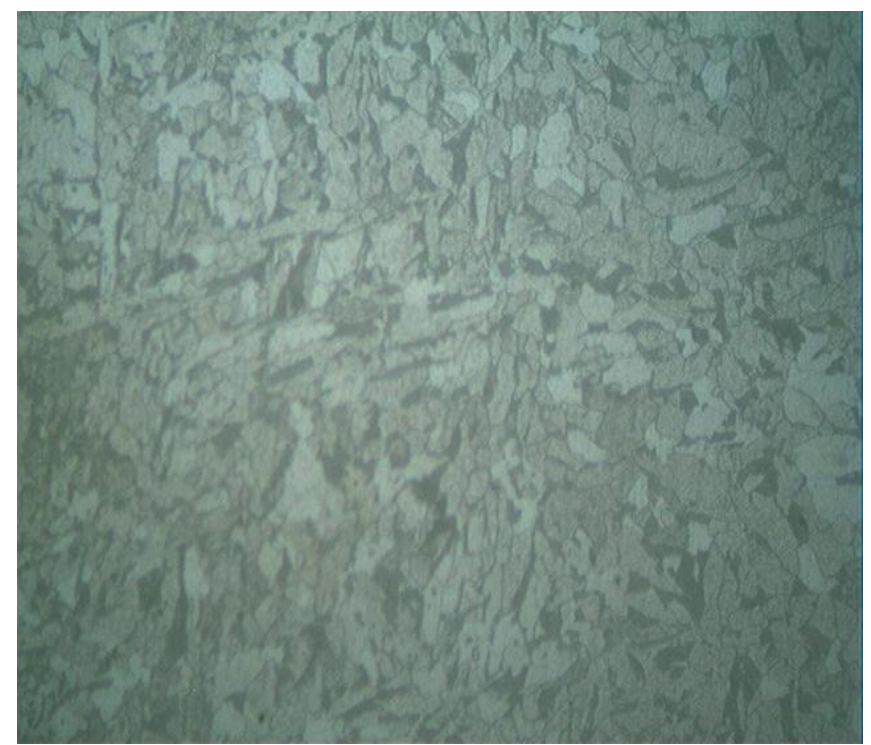

Fig -4: Microphotograph of sample B contain $50 \%$ zircon and $50 \%$ alumina $(400 \mathrm{X})$

The microphotograph of sample B shows the microstructure contains cementite and pearlite phases. Alumina mixed with zircon in the shell of mold for this experiment. Alumina has high thermal expansion compare to zircon, which cause distortion in phases, Microstructure of this experiments seems to be not uniform.

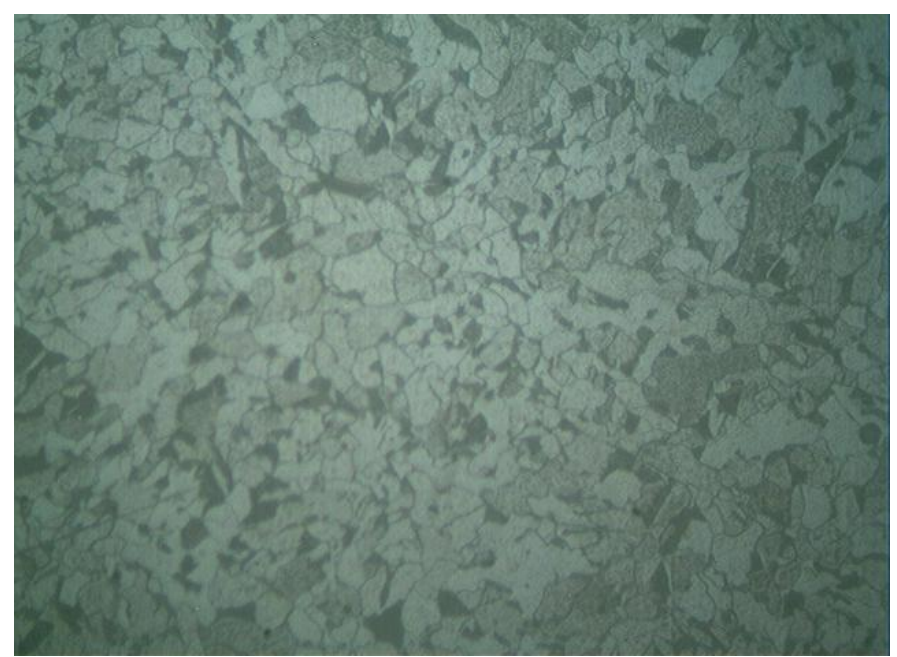

Fig -5: Microphotograph of sample C contain $70 \%$ zircon and $30 \%$ silica (400X)

The microphotograph of sample $\mathrm{C}$ reveals that the microstructure contains cementite and pearlite. In microstructure more amount of pearlite observed since the carbon percentage reduced after pouring of metal. The amount of cementite reduction leads to decrease in hardness.

\section{CONCLUSION}

In order to develop and optimize the mold material for the investment casting of low alloy steel. From the practical work conclusions are summarized as follows

1. The development of mold material like alumina with zircon and silica with zircon performed experiments successfully without any issues.

2. Alumina can be replaced partially to zircon as primary slurry material since it provides good surface finish without affecting the mechanical properties.

3. Silica with zircon produced inferior surface quality and micro characteristic.

4. $100 \%$ zircon as primary slurry produces excellent surface morphology of casted samples and provides directional solidification.

\section{REFERENCES}

[1]. V. B. John, Introduction to Engineering Materials, Palgrave Macmillan, 1992, pp. 316-320.

[2]. Prasad, Rama T. V., "Progress in investment casting", Science and Technology of casting process, Chapter-2, pp. 28-38

[3]. Balwinder singh, Pradip Kumar, B. K. Mishra, "Evaluation of Primary slurry used in ceramic shell investment casting process", International Journal of emerging technology and advance engineering, Vol-2, issue10, Oct-2012, pp. 525-529

[4]. P. C. Sharma, A text book of production Technology manufacturing processes, S. Chand \& Co, pp. 187-194, 1996 [5]. P. A. Storozhenko, G. I. Shcherbakova, D. V. Sidorov, M. S. Varfolomee, A. S. Murkina, "Corundum mold for investment casting from refractory alloy and metals", Advanced material science and engineering, Hindawi publishing corporation, Volume 2010, page 1

[6]. D. M. Kline, S. N. Lekakh, V. L. Richards, "Improving investment casting mold permeability using graphite particle", AFS transactions, 2010, American foundry society, Schaumburg, IL USA, Paper 10-087, pp. 1-7

[7]. Glenne W. Ledder, Wayne D. Pasco, Paul S. Svec, "Alumina shell molds used for investment casting in directional solidification of eutectic super alloy", United state patents, 1981, 4,247,333,

[8]. Jergy Zych, Tomasz Snopkiewicz, "Drying and hardening of ceramic molds applied in the investment casting technology investigations of the process kinetics", Metallurgy and foundry engineering, Volume 37, 2011, No1, pp. 49-51 